\title{
Popular Music and the Celtic Tiger
}

\section{Gerry Smyth \\ Liverpool John Moores University}

\section{Sing When You're Winning}

On 14 June 2012, the Republic of Ireland soccer team was comprehensively beaten 4-0 at the UEFA Euro Football Championships by the eventual winners Spain. During an on-the-pitch post-match interview for the UK's ITV network, the Irish midfielder Keith Andrews praised both the quality of the opposition as well as the 'brilliant' support of the Irish fans, who continued en masse to sing 'The Fields of Athenry' throughout the final minutes of the match. Coverage then returned to the studio where the former Republic of Ireland and Manchester United player Roy Keane (working as a regular analyst for the station during the competition) was invited to comment. He was, as is his wont, livid:

I think the players, and even the supporters, they all have to change their mentality. It's just nonsense when players speak after the game about how great the supporters are. Listen, the supporters want to see the team doing a lot better and not giving daft goals away like that. So, no, listen, I'm not too happy with all that nonsense ... I know that we're a small country and we're up against it, but let's not just go along for the sing-song every now and again. www.youtube.com/watch?v=1hB7ErOuH-s

Four days later, the Republic played Italy in their final group-stage match; the team was again well beaten, capping off a thoroughly miserable performance at the competition. Before kickoff, however, television cameras sweeping the Irish sections of the crowd halted momentarily on a group of fans holding a medium-sized Irish tricolour on which the words 'Can We Sing Now Roy?' had been written. As imminent defeat loomed towards the end of the match, 'The Fields of Athenry' once again featured strongly as part of the televisual soundtrack.

The virtual exchange between Keane and (some of) the Irish fans rehearses in symbolic form (some of) the issues attendant upon the rise and fall of the Celtic Tiger. Keane's determination to win (for which he was noted as a player); his insistence on challenging established 'mentalities'; his resistance to Ireland's traditional fate as 'happy-to-be-here losers' - all these resonate strongly in terms of an Irish generation which grew up in a context of sustained economic success and cultural confidence. At the same time, Keane's explicit indictment of those who 'just go along for the sing-song', his joyless response to the 'entertainment' on offer, and his description of Andrews' comment as 'nonsense' - all this seems out of kilter in some respects with the general 'party' atmosphere that characterised the Tiger years, as well as with a widespread impression of the Irish as good sports.

I find it interesting that this exchange took place in terms of different evaluations of the role of music in relation to Irish identity. For Keane, it appears that music is a distraction from the reality of competition; after all, it's not 'the sing-song' that he resents, but the discrepancy between singing and performance in the Irish experience. The sensible thing is to 'sing when you're winning' - hence, the famous terrace chant. The Irish response is 'nonsense' because it flies in the face of this apparently natural logic, and because it smacks of a traditional 'mentality' in which we could only sing whilst inevitably succumbing to the better endowed and the better prepared.

The designers of the 'Can We Sing Now Roy?' banner appear to have embraced an alternative reality with reference to an alternative logic - one organised in relation to ideas of 
performance, community participation, and a readiness 'to be' in the moment. Whereas Keane was affronted by the willingness of the Irish fans to continue singing in the face of ignominious defeat, it might be argued that the music itself was apparently an indication that those fans were in fact already 'winning' in terms of a different logic, a different reality, a different game - one from which Roy Keane, with his 'winning' mentality, would always be excluded.

In some senses, this is a very old debate in so far as it rehearses an opposition which has been troped in numerous different ways and contexts throughout Irish history. In another sense, however, it stands as a very modern (or perhaps 'postmodern' would be better) exchange, one that resonates strongly in terms of the ongoing troubled response of contemporary Irish popular music to the Celtic Tiger.

\section{Uncertain Economics}

Some people like to date the onset of Ireland's decisive entry into the modern world from U2's appearance on stage at the Live Aid concert in London on 13 July 1985. That performance certainly represented an iconic moment in modern Ireland's developing sense of what it was and what it could be. If I had to choose one moment to mark the onset of a new dispensation in modern Irish history, however, one text through which to observe the emergence of a new paradigm for modern Irish identity, I would have to opt for 19 November 1991, the date on which U2 released their seventh studio album, Achtung Baby! That this event occurred nearly three years before Kevin Gardiner's famous article naming the Celtic Tiger is indicative of music's extreme sensitivity with regard to paradigmatic shifts within the systems (including the economic system) that comprise any given national formation. ${ }^{1}$

Achtung Baby! represented the sound of a band growing up, leaving home and embracing everything that the modern world had to offer in the way of sensory, intellectual and emotional stimulation (Smyth 2001, 159-87; Smyth 2005, 96-102). This was a radical gesture for two reasons: firstly, because up until that time U2 had deliberately and self-consciously traced the conscience of the nation from which it emerged; and secondly, because that same nation had been characterised by circumspection - not to say restriction - in precisely those areas with which the band was now looking to engage. After a decade and more in which the limits of U2's musical questing had been set by discourses of 'expression', 'authenticity' and 'truth', on Achtung Baby! the band courageously broached the possibility of a new aesthetics - one organised around ideas of uncertainty, performativity and the moral compromises attendant upon living in the modern world. In short, Achtung Baby! dramatised the existential standoff between success and failure before the Celtic Tiger rendered that dilemma a reality for Ireland itself.

U2 continued to pursue this line throughout the 1990s and into the new millennium, each new release offering (amongst other things) an indication of the directions in which Ireland's moral compass was likely to swing in response to rapidly changing circumstances. This was an effect, moreover, of both sound and words - which is to say, the themes engaged by Bono in his role as singer, and the music through which those themes were articulated and explored by the remainder of the band and the production team. Taken together, the prevailing ethos of the music is uncertainty with regard to all the ideas and the values that once sustained a particular view of the world. In a typically postmodernist coup, however, that very quality can (as the title track from 1993's Zooropa puts it) 'be a guiding light' - indeed, in the absence of any other credible mechanism, it must be (U2 1993). 
I would like to suggest that the quality of 'uncertainty' as encountered in the music of U2 during the 1990s is a direct analogue in the cultural/emotional sphere of ideas relating to 'mobility', 'flexibility', even 'deregulation', in the economic/political sphere. ${ }^{2}$ Beyond issues concerning the relations between the different spheres of activity comprising contemporary society, however, such a suggestion raises difficult questions - many of which turn on the difference between those small words can and must. Did the Republic embrace Tiger economics because back in the early 1990s there was no other game in town, and because, after decades of economic underperformance, those in power owed it to the nation to pursue 'success' at whatever cost in other areas of national life? Can we, from a post-crash perspective, really blame those who failed to find the 'certainties' in an uncertain world, or to ditch with such alacrity such 'certainties' as were already in place? Was the Celtic Tiger - its rise, short reign and ignominious demise - unavoidable in the 'light' of wider shifts in the global organisation of capital? Is 'uncertainty' - once so sexy and attractive - now entirely tainted, a sign of moral turpitude and cultural decadence? And if so, how long will it remain so?

In retrospect, U2's view of the benefits of 'uncertainty' (when translated into politicoeconomic discourse) turned out to be overly optimistic. It may be simply tautological to say that postmodern capitalism is a good thing when it works in your favour; nevertheless, it is a bitter lesson in logic and rhetoric that everyone in Ireland has been obliged to learn.

\section{Not 'Bad'}

Like anyone born in the 1950s or early 1960as, the individual members of U2 had experience of pre-Tiger Ireland, and this has coloured their response to, and engagement, with the kind of country that emerged during and since the 1990s. After all, the band had grown up and come to maturity in a very different country - an Ireland of the 'Troubles', of determined clerical power, of cultural conservatism, social polarisation, political venality and economic malaise. This was the country described in 'Bad' in terms of 'desperation, dislocation, separation, condemnation, isolation, desolation' - an island of police and priests, heroin and emigration, moving statues and attritional war (U2, 1984). The experience of living in such a time and place afforded the band an ironic perspective on the supposedly new, supposedly 'real' Ireland that followed hard on the heels of Achtung Baby! and Zooropa.

U2 anticipated the Celtic Tiger, and in some senses provided a language with which to begin to approach and articulate the new moral and socio-economic dispensation. They were never of the Celtic Tiger, however, in a way that a band like The Script so clearly were. This Dublin three-piece were part of Ireland's end-of-the-century baby boomer generation, members of an elite 'Expectocracy' (McWilliams 2005, 52-67) which has been educated in, and inculcated with, a range of values and opinions vastly different from those of their parents. This is something, moreover, that is apparent in every aspect of the band's identity: lyrics, music, iconography and ethos.

Like U2 before them, on their eponymous debut album The Script tried to bridge the gap between local and general frames of reference. There are recognisable Irish allusions, such as the husband who 'hits the jar' in 'Together We Cry', and the 'Guinness' and 'Grafton Street' of 'Before the Worst' (The Script 2008). At the same time, the album is comprised of songs detailing a range of generally downbeat perspectives (pain, regret, guilt, loss) that are not nation-specific. The 'man who can't be moved' may be standing on a corner in Dublin; but he just as likely to be in Newcastle or Glasgow or Cardiff, or indeed in Boston, Sydney or Toronto. In this regard, The Script were merely working within in a long tradition of 'Irish 
popular music-makers' who have tried to negotiate the conflicting forces operating within that very designation. ${ }^{3}$

But what really signals The Script as a popular musical articulation of the Celtic Tiger is the sound of the music - which is to say: a studio-honed, blue-eyed $\mathrm{R} \& \mathrm{~B}$, the signature element of which is Danny O'Donoghue's rich, supple voice and his highly stylised vocal delivery. Other Irish acts had broached this sound previously, most notably the Dubliner Samantha Mumba in her short-lived career of the early 2000s. It is the sound of a generation that grew up listening to Destiny's Child, Justin Timberland and Christina Aguilera; for whom the discourses of American hip-hop and rap were entirely conventional aspects of the international musical soundscape; and for whom the elaborate vocal techniques evolved from earlier popular music traditions (most centrally, soul) represented the 'natural' context within which to develop a vocal interpretation.

Irish bands had been playing soul and related genres since the 1960s. The story of Belfast youth's grieved reaction to the death of Otis Redding in 1967 is well-known, and the city's close identification with that particular brand of African-American popular music must surely have influenced Van Morrison's later description of his own music as a kind of 'Irish soul'. Later still, the fictional Commitments purveyed a brand of Dublin soul, and tried to make common cause with the genre's ideological and iconographical roots in working-class pride and social exclusion (Doyle 1987; Smyth 2009, 65-83). As in the case of the American originals, however, these sources are related to, but different in a number of key respects from, the version of R\&B that began to emerge during the 1980s and became such a powerful influence on global popular music during the last decade of the millennium - the same decade that saw the emergence of the Celtic Tiger.

Of course, The Script are not a real R\&B band (whatever that might mean). They are in fact entirely typical in so far as shades of many different popular genres and styles (even U2) may be identified in their music. Certainly, however, some of the core attitudes and assumptions of $\mathrm{R} \& \mathrm{~B}$ have seeped into the musical, lyrical and iconographical identity of the band. Once there, they cross-fertilized with a cluster of attitudes and assumptions born of the Celtic Tiger - born, that is to say, of living in a society powered by what seemed at the time like an unstoppably successful economy. One might refer to this as a 'structure of feeling', a 'mentality', an 'ideology', a 'politics of truth', or some other designation; the point is that a society infuses the culture it produces in a myriad explicit and implicit ways; and the Celtic Tiger infuses the sound of The Script in ways that they would hardly acknowledge and would in truth probably wish to deny.

In short, the sound of The Script is the sound of the Celtic Tiger-even when the band is singing about 'bad things'. The various 'failures' articulated by the various protagonists on the first album, for example, are belied by the ideology of expectation and attainment that underpins the music itself. It is the sound of success pretending to fail. It is interesting to note, for example, that 'the man who can't be moved' is only playing the part of a homeless person, with his sleeping bag, his cardboard and his politely recalcitrant attitude towards the police. In fact, he is 'not broke', only broken-hearted; there is a hole in his heart but not in his shoes. The girl jumps on an aeroplane to stay with friends in London; the guy speeds through the dark streets in his car looking for her; the music surges, perfect in its texture and in its resonance. The generation which won tells a story about failure, and wins again. 
The Script was released on 8 August 2008, a few weeks before Brian Cowen's government declared the Republic to be in recession. We all know what happened after that.

\section{Dreams and Songs to Sing}

The particular song which called forth Roy Keane's ire deserves some consideration. 'The Fields of Athenry' is a modern ballad written in 1979 by Dublin singer-songwriter Pete St. John. It's set during the Great Famine (1845-50), and tells the story of a man named Michael who is transported to Australia after being caught stealing food for his starving family. The song was already familiar to Irish record-buyers through versions by artists such as Danny Doyle and Barleycorn before a version recorded in 1983 by Paddy Reilly became, for no immediately apparent reason, an Irish musical phenomenon, catching the ear of the recordbuying public and staying in the national record charts for over a year.

Since then the song has continued to grow in fame and familiarity. Not unexpectedly, many recording artists have attempted to capitalise on its popularity by recording versions in a wide range of styles. ${ }^{5}$ More interestingly and more significantly, 'The Fields of Athenry' has been adopted and reproduced in a wide range of public contexts - especially sporting events. These days one may hear it sung at rugby matches, soccer matches and GAA. matches; in Glasgow and Galway, Dublin and London, New York and Boston. In England 'The Fields of Anfield Road' forms the melancholy backdrop to Liverpool Football Club's fading glory. Alongside the almost equally ubiquitous chant of 'Olé, Olé, Olé', St. John's composition was heard during the London Olympics as the euphoric soundtrack to Katie Taylor's memorable victory in the Women's Lightweight Boxing competition. The fact is that 'The Fields of Athenry' has assumed a protean profile within the international soundscape which is far above and beyond either its original context or the various attempts to capture it in textual (that is, recorded) form.

The emergence of 'The Fields of Athenry' as an Irish sporting anthem seems a strange development, especially when one considers the tragic nature of the story it relates. A multitude of nineteenth-century Irish woes are covered in three shortish verses, including poverty, hunger, subjection, separation, loneliness, imprisonment and transportation. To describe such a song as 'downbeat' would be understated; it is in fact a litany of Irish 'failures' - political, personal, cultural, economic. The piece is 'traditional' in terms of its musical discourses, certainly, in as much as it sounds like an Irish ballad. But it is also traditional in terms of its subject matter: a typical 'Irish' story of dispossession and defeat. St. John employs an interesting image to expedite the pathos of the narrative: young lovers dreaming and singing (real or metaphorical) songs. With the disappearance of her dreams along with her husband, however, the character of Mary is left with no songs to sing other than the lament that is 'The Fields of Athenry'.

As pointed out above, all this seems a long way removed from Celtic Tiger Ireland and its fetishisation of success in the forms of acquisition and conspicuous consumption. The question is: how did this very traditional ballad come to occupy the role it does in contemporary Irish popular culture at this particular time?

A number of possibilities suggest themselves. Firstly, it may be observed that it is usually only the chorus that is sung at these public sporting events; the verses, wherein the worst of the depredations are recounted, tend to be beyond either the ability or the ambition of largescale spontaneous choirs such as the one that sung continuously for nearly ten minutes at the end of the Spain-Ireland game mentioned at the outset of this essay. The opening word may 
be 'low', but it is in fact sung on one of the highest notes of the melody, and this creates an oddly uplifting effect which belies the downbeat lyric. Added to this is the fact that the melody as a whole always repairs to the major key in which the song is set; so, whereas the lyric offers only 'hope' as the one positive element within a landscape of despair, the melody brings the community of singers (and listeners) 'home' in a way that's both predictable and comforting. The contradiction between melody and lyric, and the semiotic predominance of the former over the latter in performance, may be one of the reasons why 'The Fields of Athenry' has been so enthusiastically adopted by a range of Irish and Irish-related sporting audiences.

Secondly, and related to this, there is the fact of the song's amenability (which it shares with most ballads) to potentially unrestricted unison performance: this means that as many people as wish to can join in. Of course, this is in the nature of modern sports-fan culture: there is no room for individual expression within a singing (or chanting) crowd. In this respect, crowd singing belongs to a form of pre-modern (or pre-modernist) cultural expression in which the community, rather than the individual, constitutes the Subject of meaning. In this respect, we might say that 'The Fields of Athenry' represents a form of communal vernacular culture which is at odds with modernist individualism, and this has helped it accrue a kind of residual value within a cultural economy in which the old and the new, the imagined past and the imagined future, existed alongside each other as powerful influences. It's this effect which qualified Celtic Tiger Ireland to be described as a 'postmodernist' society, one in which history (past, present and future) operated as an active element within the lives of all its constituent members.

So, in some sense, crowd-based unison performance of 'The Fields of Athenry' represents a form of nostalgia for an imaginary pre-Tiger Ireland. It's a way of showing that we have not forgotten who we are, or where we've come from, or what has gone into our historical development. But such is, as ever, an anxious strategy because the very performance acknowledges and confirms an ineluctable difference between then and now, between an ideal (imaginary) event located somewhere else in time and space, and the one that's occurring now, here, in the present. Irish fans were widely commended for the prolonged duration of their singing in the face of inevitable defeat by Spain. There is a sense, however, in which all those repetitions of the chorus of 'The Fields of Athenry' represents a kind of hysterical response to trauma - not the trauma of immediate sporting defeat, but the trauma of separation (rehearsed again and again with every repetition) from the community's formative experience.

\section{OMG You Guys!!!}

One piece of music that did not feature in the repertoire of the Irish fans at the UEFA 2012 competition was 'Put the Green Cape On', a charity single released by the pop phenomenon known as Jedward. This was a remix of 'Lipstick', the song with which that group represented Ireland at the Eurovision Song Contest in 2011. Written by Irish radio DJ Colm Hayes, the new lyric extols the virtues of the Irish football team, and invites the listener to join an army of green-caped super-supporters in order to put 'Europe on the run' and help Ireland win the competition. The minor key and high tempo give the record a martial feel which is in keeping with the lyric's mock-heroic pretentions. The vocal is a highly-modified unison performance by the two singers which relies for effect not on traditional performance values of 'interpretation' or 'expression' but on studio-honed editing, especially in the areas of timing and tuning. 
There was no sign during the team's three games at UEFA 2012 of 'Put the Green Cape On' replacing either 'The Fields of Athenry' or the traditional chant of 'Olé, Olé, Olé' (which it references in its own lyric) as a performance option for Irish fans. This may have been because the song was not conducive to mass performance, but it is more likely to have been a reflection of the distance between the aesthetic values of (Irish) football and the particular kind of popular music with which that particular group is associated. The fact is that Jedward tend to polarise opinion in Ireland, with the majority tending towards a negative estimation of their worth as performers and as representatives of modern Irish identity. And yet, there are qualities in their music, in their image and even in their composite personality which suggest something of the essence of the Celtic Tiger (even though they emerged only after the demise of that phenomenon). Indeed, from the perspective of modern Irish society 'Jedward' asks more questions of us than we could ever ask of them.

'Jedward' is the name assumed by identical twin brothers John and Edward Grimes, born ten minutes apart in Dublin in 1991. They first emerged into public view in 2009 when they appeared on the British talent show The X Factor. Although they did not win, the brothers won the support of Irish impresario Louis Walsh (who featured as judge and mentor on the show), and under his management they have gone on to develop a strong media presence in both Ireland and the United Kingdom. At the time of writing Jedward have, amongst other things, released three albums, represented Ireland at Eurovision on two occasions, and appeared on numerous television programmes, including their own day-time children's show. The twins' semiotic signatures - extended blond quiff and 'OMG!' salute - are ubiquitous, like a colourful rash all across television, radio and internet. Like it or not, dear reader, we are all to some degree or other inhabitants of 'Planet Jedward'.

I remarked above that the sound of The Script is the sound of the Celtic Tiger; as an addendum it might be observed that the soul of Jedward is the soul of the Celtic Tiger young, brash, loud, four eyes focused firmly on the prize, 'talented' principally in the ability to exploit all available systems (tax laws on the one hand, technology on the other) in pursuit of the underlying goal. One senses a canny intelligence behind all the posing and the inane chatter; if this is partly the presence of Louis Walsh, the influence of two well-educated, middle-class, highly-focused young men should not be discounted. Growing up in the era of hugely successful Irish pop acts such as Boyzone and Westlife, Jedward's ambitions were further expedited by the advent of mass-market 'Talent TV' and so-called 'Celebrity' culture - genres for which the twins might have been invented.

There is at the same time a kind of hollowness at the heart of the Jedward enterprise, one which echoes the society that produced them, and which produces a kind of anxiety that is above and beyond the mere antipathy their work excites in so many. John and Edward never really 'say' or 'sing' anything; their words are always 'exclaimed' or 'quoted' in a kind of faux-American accent, with an affected intonation as if every enunciation were of seminal significance. One of the effects of this is to create the impression that there is no distance between the reality the boys inhabit and the various realities into which they project themselves as singers and personalities. The anxiety arises in the first instance from the listener's uncertainty as to whether this is ironic or 'real' - that is, whether the imaginary quotation marks constitute the reality within which 'Jedward' exists, off-screen as well as on, off-mic as well as on. And if 'Jedward' are real, does this extend to the society that produced them, as well as to the subjects - you, reader, as well as I - that have an investment of some kind or degree in that society? 
To employ a different metaphor, Jedward's mask is only maintained with an effort that becomes increasingly obvious the more one is exposed to them. This creates a mood of hysteria - one in which the listener / watcher is implicated - as if everything is constantly on the brink of collapse, and only perpetual movement (of body and language) and a kind of willed ignorance can keep the whole edifice from imploding on its own essential absence. Such an image brings us back once again to the Celtic Tiger.

\section{Conclusion}

One of the lines in 'Put the Green Cape On' exhorts the reader to 'forget the bank bailout'. No doubt that is precisely what the travelling Irish fans were attempting to do; although how people from a country in deep recession managed to pay for travel, accommodation, subsistence and tickets, and what they faced when they returned, are matters worth considering. In the meantime we might observe that this particular line represents a moment of acknowledgement between the world of popular culture - in particular, the world of popular music - and the economic realities which determine all our lives. Such moments were once rare enough in contemporary Ireland. For the majority of people, after all, popular music is that to which you turn precisely in order to forget about such realities. Popular music appears to remind us that humankind does not live by bread alone, and that there are species of emotional and spiritual experience which remain impervious to merely material concerns.

The truth was always very different, of course. Indeed, I would contend that there is no area of popular culture that is more mediated by economic reality than music; as a consequence, there is no area of popular culture that is more politically sensitive than the music that is consumed by the mass of the population. As Jacques Attali has written: 'Music, the quintessential mass activity, like the crowd, is simultaneously a threat and a necessary source of legitimacy; trying to channel it is a risk that every system of power must run (1985, p. 14). The burden of this essay has been that it is precisely in the channelling of its popular music, and in the various risks (aesthetic, psychological, material) attending such an activity, that the reality of the Celtic Tiger and its aftermath continues to be most fully and most sensitively engaged.

In an article written during the heyday of the Celtic Tiger, I offered a definition of music (following Attali) as the political organisation of noise. 'We ignore music at our peril,' I claimed, 'for at the same time as it affords us the most accurate impression of how things are, it offers us the most enabling impressions of how things might be - for good and bad, in sickness and in health' (2004, 10, original emphases). I claim no prescience (although the references to 'bad' and 'sickness' came home to roost sooner than probably anyone expected), but the main point holds good: U2 may have become tragically unfashionable; The Script may have discovered a new kind of Irish-American sound; 'The Fields of Athenry' may have been converted from sentimental ballad to sporting phenomenon; and Jedward may be nothing more than a bad joke. For those with ears to hear, however, somewhere amongst all this music may be discerned echoes of our recent past and our imminent future; somewhere amongst all this noise we should be able to get an idea of how we got where we are and of where we might be heading. 


\section{Notes}

1 In Noise: The Political Economy of Music, trans. Brian Massumi (1977; Manchester University Press, 1985), Jacques Attali writes: 'Music is prophecy. Its styles and economic organization are ahead of the rest of society because it explores, much faster than material reality can, the entire range of possibilities in a given code' (p. 12).

2 In The Condition of Postmodernity: An Enquiry into the Origins of Cultural Change (Oxford: Basil Blackwell, 1989), David Harvey defined postmodernism with reference to 'the emergence of more flexible modes of capital accumulation and a new round of 'time - space compression' in the organization of capitalism' (p. vii).

3 See Smyth, Noisy Island, pp. 30-45, on the pattern which saw an early generation of Irish popular musicians (such as Rory Gallagher, Van Morrison and Thin Lizzy) seek their success in the UK and elsewhere.

$4 \quad$ In Nuala O'Connor's Bringing It All Back Home: The Influence of Irish Music (London: BBC Books, 1991), Morrison is quoted as claiming 'that soul music originally came from Scotland and Ireland' (p. 6). I am grateful to the poet Gerald Dawe for the story regarding Belfast's response to the death of Otis Redding.

5 'The Fields of Athenry' has featured in the stage shows of international artists such as Bruce Springsteen and Take That.

\section{Works Cited}

Jacques Attali, Noise: The Political Economy of Music, trans. Brian Massumi (1977; Manchester University Press, 1985)

Roddy Doyle, The Commitments (1987), vol. I of The Barrytown Trilogy (Minerva, 1992)

David Harvey, The Condition of Postmodernity: An Enquiry into the Origins of Cultural Change (Oxford: Basil Blackwell, 1989)

Jedward, 'Lipstick' (Universal Music Ireland, 2011)

--- 'Put the Green Cape On' (Universal Music Ireland, 2012)

David McWilliams, The Pope's Children: Ireland's New Elite (2005; London: Pan, 2007)

Nuala O'Connor, Bringing It All Back Home: The Influence of Irish Music (London: BBC Books, 1991)

The Script, The Script (Sony, 2008)

Gerry Smyth, Space and the Irish Cultural Imagination (Basingstoke: Palgrave, 2001)

--- 'Introduction: The Isle is Full of Noises - Music in Contemporary Ireland', in Gerry Smyth (ed.) Music in Contemporary Ireland: A Special Edition of the Irish Studies Review 12.1 (April 2004), 3-10

--- Noisy Island: A Short History of Irish Popular Music (Cork: Cork University Press, 2005) 
--- Music in Irish Cultural History (London: Irish Academic Press, 2009)

U2, The Unforgettable Fire (Island, 1984)

--- Zooropa (Island, 1993)

5387 (with Notes and Works Cited) 